\title{
Inhibitory effects of Akebia quinata ethanol extract on TNF- $\alpha$-mediated vascular inflammation in human aortic smooth muscle cells
}

\author{
HYUN JUNG KOO, YOON YOUNG SUNG and HO KYOUNG KIM \\ Basic Herbal Medicine Research Group, Korea Institute of Oriental Medicine, Daejeon 305-811, Republic of Korea
}

Received August 3, 2012; Accepted November 7, 2012

DOI: $10.3892 / \mathrm{mmr} .2012 .1193$

\begin{abstract}
Atherosclerosis is a chronic inflammatory disease of the arterial wall. The expression of adhesion molecules in aortic smooth muscle cells facilitates the accumulation of transmigrated leukocytes within the atherosclerotic vascular wall. The stem of Akebia quinata (A. quinata) has previously been used as a crude drug for treating urinary disorders and inflammatory disease in Korea, China and Japan. In the present study, we investigated the effect of an A.quinata ethanol extract (AQEE) on the expression of adhesion molecules and cyclooxygenase-2 (COX-2) in tumor necrosis factor $\alpha$ (TNF- $\alpha)$-induced human aortic smooth muscle cells (HASMCs). The results of the present study demonstrated that AQEE attenuated intercellular adhesion molecule 1, E-selectin and COX-2 expression in TNF- $\alpha$-stimulated HASMCs and inhibited THP- 1 cell adhesion to activated HASMCs. Furthermore, AQEE suppressed the TNF- $\alpha$ induced phosphorylation of p38 mitogen-activated protein kinase (MAPK) and reduced nuclear factor $\kappa \mathrm{B}$ (NF-кB; p65) nuclear translocation. The present study demonstrated that AQEE possesses anti-inflammatory properties and regulates TNF- $\alpha$-induced expression of adhesion molecules by inhibition of the $\mathrm{p} 38 \mathrm{MAPK} / \mathrm{NF}-\kappa \mathrm{B}$ signaling pathway.
\end{abstract}

\section{Introduction}

Atherosclerosis is a chronic inflammatory disease of the arterial wall that is characterized by the formation of atherosclerotic lesions (1-3). In the early stages of atherosclerosis,

Correspondence to: Dr Ho Kyoung Kim, Basic Herbal Medicine Research Group, Korea Institute of Oriental Medicine, 483 Exporo, Yuseong-gu, Daejeon 305-811, Republic of Korea

E-mail: hkkim@kiom.re.kr

Abbreviations: AQEE, Akebia quinata ethanol extract; CE, cytoplasmic extracts; COX-2, cyclooxygenase 2; HASMC, human aortic smooth muscle cell; ICAM-1, intercellular adhesion molecule 1; MAPK, mitogen-activated protein kinase; NE, nuclear extracts; $\mathrm{NF}-\kappa \mathrm{B}$, nuclear factor $\kappa \mathrm{B}$; TNF- $\alpha$, tumor necrosis factor $\alpha$

Key words: Akebia quinata, atherosclerosis, inflammation, adhesion molecules, cyclooxygenase-2 monocyte adhesion and migration to the arterial wall is mediated by adhesion molecules that are expressed on vascular cells, including intercellular adhesion molecule 1 (ICAM-1) and E-selectin (2,4-6).

Previous studies demonstrated the importance of aortic smooth muscle cells in the development of atherosclerosis (1,7-10). Specifically, adhesion molecules expressed in smooth muscle cells in the intima of atherosclerotic lesions appear to facilitate the accumulation of transmigrated leukocytes within the atherosclerotic vascular wall (11-13). Adhesion molecule expression is induced by the proinflammatory cytokine TNF- $\alpha$, which is crucial for the pathogenesis and progression of atherosclerosis $(10,14)$.

The stem of Akebia quinata (A.quinata; Lardizabalaceae) has been used as a crude drug for treating urinary disorders and inflammatory disease in traditional Korean, Chinese and Japanese Kampo medicine (15). A. quinata contains saponins (triterpene and triterpene glycosides), chemical compounds associated with a number of biological activities $(16,17)$. However, a limited number of studies have addressed the biological and pharmacological effects of $A$. quinata. In particular, the antiatherogenic effects of A. quinata in aortic smooth muscle cells remain unclear.

In the present study, the effect of A.quinata ethanol extract (AQEE) on TNF- $\alpha$-induced adhesion molecule expression in human aortic smooth muscle cells was analyzed. In addition, the mechanisms underlying the antiatherogenic effects of AQEE were investigated.

\section{Materials and methods}

Reagents. Antibodies against ICAM-1 and E-selectin were purchased from R\&D Systems (Minneapolis, MN, USA). Antibodies against COX-2, p65, lamin A, $\beta$-actin, phospho-p38 and p38 were purchased from Cell Signaling Technology (Beverly, MA, USA).

Cell culture. Human aortic smooth muscle cells (HASMCs) were purchased from ScienCell Research Laboratories (Carlsbad, CA, USA). Cells were cultured as monolayers in smooth muscle cell medium (ScienCell Research Laboratories) containing essential and non-essential amino acids, vitamins, organic and inorganic compounds, hormones, growth factors, trace minerals and $2 \%$ fetal bovine serum (FBS) at $37^{\circ} \mathrm{C}$ in a 
humidified atmosphere with $5 \% \mathrm{CO}_{2}$. For subculturing, cells were detached using $0.125 \%$ trypsin containing $0.01 \mathrm{M}$ EDTA. Cells from passages 2-6 were used for the study. THP-1 cells (ATCC, Manassas, VA, USA), a human myelomonocytic cell line widely used to study monocyte/macrophage biology in culture systems (18), were used in the cell adhesion assay with HASMCs. THP-1 cells were cultured in RPMI-1640 medium, supplemented with $2 \mathrm{mM}$ L-glutamine, $100 \mu \mathrm{g} / \mathrm{ml}$ streptomycin, $100 \mathrm{IU} / \mathrm{ml}$ penicillin and 10\% FBS.

Preparation and characterization of A. quinata extract. A. quinata was purchased from Omniherb Co., Ltd. (Yeongcheon, Korea) and was authenticated based on its microscopic and macroscopic characteristics by the Classification and Identification Committee of the Korea Institute of Oriental Medicine (KIOM, Daejeon, Korea). A voucher specimen has been deposited at the herbarium of the Department of Herbal Resources Research at KIOM. Dried A. quinata (200 g) was extracted twice with $70 \%$ ethanol (with 2-h reflux). The extract was then concentrated under reduced pressure at $40^{\circ} \mathrm{C}$ with a rotary evaporator. The decoction was filtered, lyophilized and stored at $4^{\circ} \mathrm{C}$ until use. The lyophilized powder was dissolved in $10 \%$ dimethyl sulfoxide and then filtered through a $0.22-\mu \mathrm{m}$ syringe filter to make the stock solution. The yield of the dried extract from the starting crude materials was $12.01 \%$.

Cell viability. Cells were seeded in 96-well flat-bottom plates $\left(2 \times 10^{4}\right.$ cells/well $)$ and incubated in the presence of various concentrations of $\operatorname{AQEE}(0,10,50$ and $250 \mu \mathrm{g} / \mathrm{ml})$ for $8 \mathrm{~h}$. Cell counting Kit-8 (CCK-8) reagent (Dojindo, Kumamoto, Japan) was added to each well and incubated for $1 \mathrm{~h}$. Absorbance was measured at $450 \mathrm{~nm}$ using a Benchmark Plus microplate reader (Bio-Rad Laboratories, Hercules, CA, USA). The experiment was performed in triplicate and cell viability was calculated relative to that of the control.

THP-1 adhesion assay. Adhesion of THP-1 cells to HASMCs was measured as described previously (19). Briefly, HASMCs were grown in 96-well plates and pretreated with AQEE $(0$, 10,50 and $250 \mu \mathrm{g} / \mathrm{ml}$ ) for $2 \mathrm{~h}$ at $37^{\circ} \mathrm{C}$. Cells were washed with medium and then incubated with fresh growth medium containing TNF- $\alpha(10 \mathrm{ng} / \mathrm{ml})$. Following $8 \mathrm{~h}$, the medium was removed from the wells and calcein AM-labeled THP-1 cells $\left(2 \times 10^{5}\right.$ cells $\left./ \mathrm{ml}\right)$ in $0.2 \mathrm{ml}$ medium were added to each well. Following 1-h incubation at $37^{\circ} \mathrm{C}$ in $5 \% \mathrm{CO}_{2}$, the microwells were washed twice with $0.2 \mathrm{ml}$ warm medium and the number of adherent cells was detected by microscopy. Each experiment was performed in triplicate.

Cell surface enzyme-linked immunosorbent assay (ELISA). The surface expression of adhesion molecules in HASMCs was quantified by ELISA. Cells were seeded in 96-well flat-bottom plates $\left(2 \times 10^{4}\right.$ cells/well), grown to confluence and pretreated with AQEE $(0,10,50$ and $250 \mu \mathrm{g} / \mathrm{ml})$ for $2 \mathrm{~h}$ at $37^{\circ} \mathrm{C}$. The cells were then washed with medium and incubated for $8 \mathrm{~h}$ with fresh growth medium containing TNF- $\alpha(10 \mathrm{ng} / \mathrm{ml})$. Following incubation, the cells were washed with phosphate-buffered saline (PBS, pH 7.4) and fixed with $0.1 \%$ glutaraldehyde for 30 min at $4{ }^{\circ} \mathrm{C}$. Bovine serum albumin (BSA; $1.0 \%$ in PBS) was added to the cells to reduce non-specific binding. The
$\mathbf{A}$

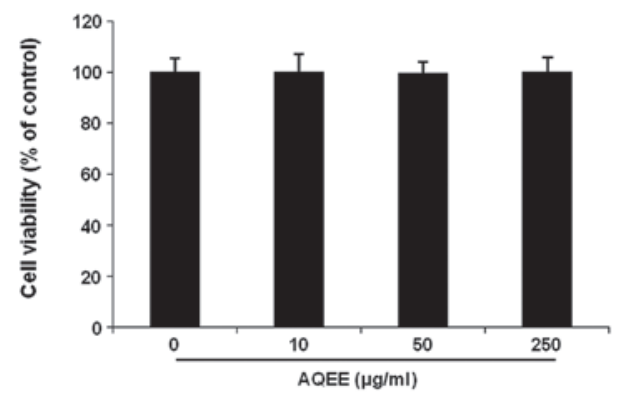

B

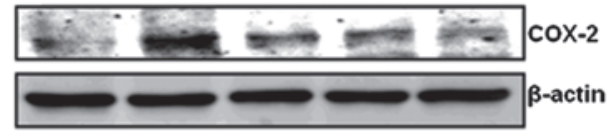

Figure 1. Effect of AQEE on cell viability and COX-2 expression in HASMCs. (A) Analysis of cell viability using the CCK-8 assay following $8 \mathrm{~h}$ treatment with various concentrations of AQEE. Results are expressed as the mean \pm SEM $(n=3)$. (B) Western blot analysis of COX-2 expression in HASMCs pretreated with AQEE (10-250 $\mu \mathrm{g} \mathrm{ml})$ for $2 \mathrm{~h}$ and then stimulated with TNF- $\alpha(10 \mathrm{ng} / \mathrm{ml})$ for $8 \mathrm{~h}$. $\beta$-actin was used as an internal control. AQEE, Akebia quinata ethanol extract; HASMCs, human aortic smooth muscle cells; COX-2, cyclooxygenase 2 ; TNF- $\alpha$, tumor necrosis factor $\alpha$.

cells were then incubated overnight at $4^{\circ} \mathrm{C}$ with primary monoclonal antibodies against ICAM-1 or E-selectin $(0.25 \mathrm{~g} /$ $\mathrm{ml}$, diluted in blocking buffer). The following day, cells were washed with PBS and incubated with a horseradish peroxidase-conjugated goat anti-mouse $\operatorname{IgG}$ secondary antibody $(1 \mu \mathrm{g} / \mathrm{ml}$, diluted in PBS). The cells were then washed with PBS and exposed to the peroxidase substrate (p-nitrophenyl phosphate, $1 \mathrm{mg} / \mathrm{ml}$ in $0.1 \mathrm{M}$ glycin buffer, $\mathrm{pH}$ 10.4, containing $1 \mathrm{mM} \mathrm{MgCl}{ }_{2}$ and $1 \mathrm{mM} \mathrm{ZnCl}$ ). Absorbance was measured at $405 \mathrm{~nm}$ using an EnVision 2103 Multilabel Plate Reader (Perkin-Elmer, Wellesley, MA, USA). Absorbance values of the isotype-matched control antibody were used as the blank and subtracted from the experimental values.

Western blot analysis. To determine the expression of COX-2, ICAM-1, E-selectin, phospho-p38 and p38, HASMCs were pretreated with AQEE $(0,10,50$ or $250 \mu \mathrm{g} / \mathrm{ml})$ for $2 \mathrm{~h}$. Cells were washed with medium and incubated with fresh growth medium containing TNF- $\alpha(10 \mathrm{ng} / \mathrm{ml})$ for $30 \mathrm{~min}$ or $8 \mathrm{~h}$. Following treatment, cells were washed twice in PBS and lysed in ice-cold lysis buffer [50 mM Tris-HCl, pH 7.4; 150 mM NaCl; 1 mM EDTA; $0.5 \%(\mathrm{v} / \mathrm{v}) \mathrm{NP}-40$; and $0.1 \%(\mathrm{w} / \mathrm{v}) \mathrm{SDS}]$ containing protease inhibitor cocktail (Roche Diagnostics Corp., Indianapolis, IN, USA) for $1 \mathrm{~h}$. Lysates were collected following centrifugation at $1,500 \mathrm{x} \mathrm{g}$ for $10 \mathrm{~min}$ at $4^{\circ} \mathrm{C}$. To evaluate the nuclear translocation of NF- $\mathrm{KB}$ p65 subunit, HASMCs were pretreated with AQEE $(0,10,50$ or $250 \mu \mathrm{g} / \mathrm{ml})$ as previously described and then stimulated with TNF- $\alpha$ for $4 \mathrm{~h}$. Cytosolic and nuclear extracts were prepared using the Nuclear Extract kit (Active Motif, Carlsbad, CA, USA) according to the manufacturer's instructions. Protein concentration was determined using the Bio-Rad protein assay (Bio-Rad Laboratories) with BSA as the standard. Protein lysates $(20 \mu \mathrm{g})$ were separated by $10 \%$ SDS-PAGE, electrophoretically transferred to Immobilon polyvinylidene difluoride membranes (Amersham, Arlington Heights, IL, USA) and probed with the appropriate antibodies. Blots were developed using an enhanced chemoluminescence kit (Amersham). In all immunoblotting experiments, the blots 

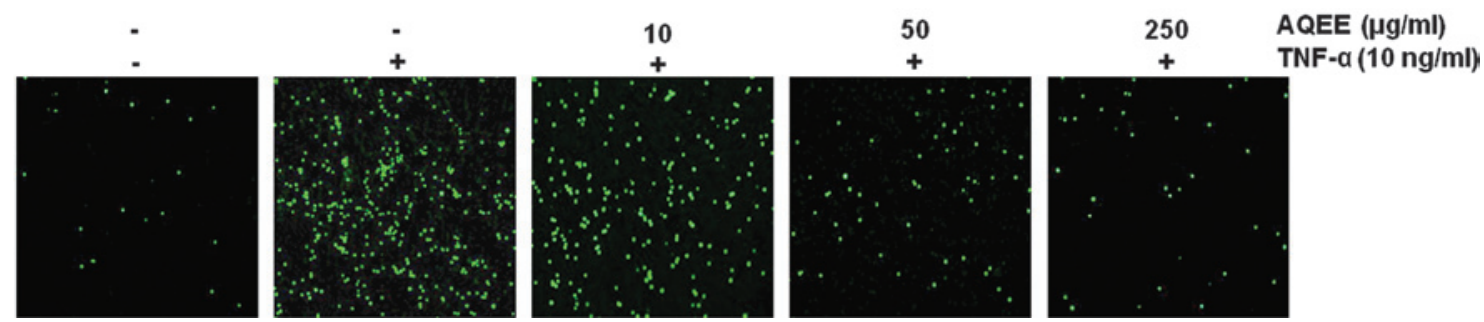

Figure 2. THP-1 adhesion assay. Inhibitory effects of AQEE on monocyte adhesion to TNF- $\alpha$-stimulated HASMCs. Confluent HASMCs were pretreated for $2 \mathrm{~h}$ with AQEE and then incubated with TNF- $\alpha(10 \mathrm{ng} / \mathrm{ml})$ for $8 \mathrm{~h}$. Calcein AM-labeled THP-1 cells were added to the HASMC monolayer and allowed to adhere for $1 \mathrm{~h}$. Adhesion of fluorescence-labeled THP-1 cells to HASMCs was detected by microscopy. AQEE, Akebia quinata ethanol extract; HASMCs, human aortic smooth muscle cells; TNF- $\alpha$, tumor necrosis factor $\alpha$.
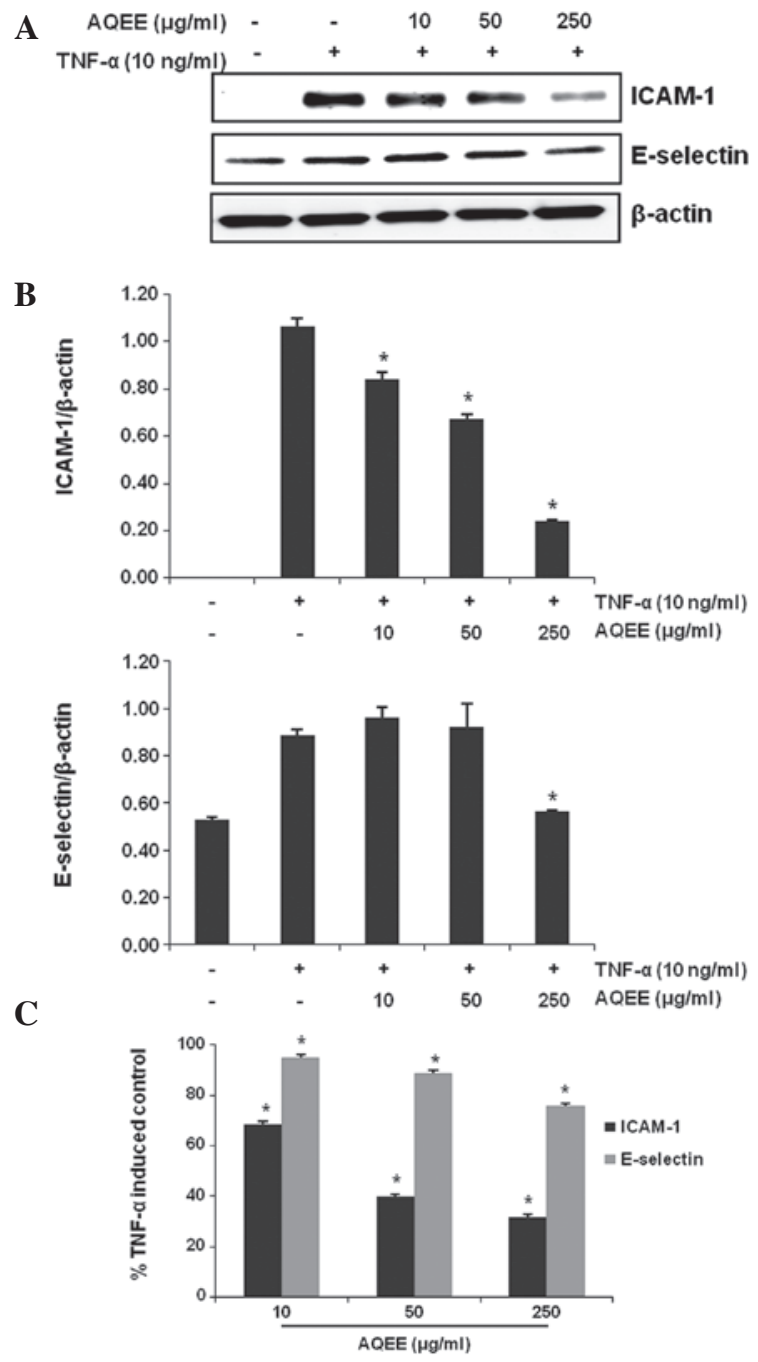

Figure 3. Effects of AQEE on TNF- $\alpha$-induced upregulation of adhesion molecules. (A) Western blot analysis of ICAM-1 and E-selectin protein levels in cells following pretreatment with AQEE $(10-250 \mu \mathrm{g} / \mathrm{ml})$ and stimulation with TNF- $\alpha(10 \mathrm{ng} / \mathrm{ml})$ for $8 \mathrm{~h}$. $\beta$-actin was used as an internal control. (B) Densitometry analysis of the western blots. (C) ELISA analysis of the surface expression of ICAM-1 and E-selectin in HASMCs. Results are presented as the percentage of TNF- $\alpha$-induced adhesion molecule expression and expressed as the mean \pm SEM $(n=3)$. ${ }^{*} \mathrm{P}<0.05$, compared with untreated TNF- $\alpha$-stimulated cells. AQEE, Akebia quinata ethanol extract; HASMCs, human aortic smooth muscle cells; TNF- $\alpha$, tumor necrosis factor $\alpha$, ICAM-1, intercellular adhesion molecule 1.

were reprobed with an antibody against $\beta$-actin or lamin A, which were used as protein loading controls.
Statistical analysis. Results were presented as the mean \pm SEM. Group differences were determined by one-way analysis of variance, followed by modified t-test with the Bonferroni correction for comparisons between individual groups. $\mathrm{P}<0.05$ was considered to indicate a statistically significant difference.

\section{Results}

Effect of AQEE on cell viability and cyclooxygenase 2(COX-2) expression. The cytotoxic effects of AQEE on HASMCs were assessed using the CCK-8 cell viability assay. Results demonstrated that AQEE did not affect cell viability and was not cytotoxic to HASMCs at the concentrations used (Fig. 1A). The effect of AQEE on COX-2 protein expression was determined by western blot analysis. COX-2 was identified to be upregulated in TNF- $\alpha$-stimulated cells. AQEE reduced TNF- $\alpha$-induced COX-2 expression in a dose-dependent manner (Fig. 1B)

Effect of AQEE on TNF- $\alpha$-stimulated monocyte adhesion to HASMCs. A THP-1 adhesion assay was performed to evaluate the effect of AQEE on monocyte adherence to TNF- $\alpha$-activated HASMCs. HASMCs were pretreated with AQEE $(0,10,50$ or $250 \mu \mathrm{g} / \mathrm{ml})$ for $2 \mathrm{~h}$ prior to TNF- $\alpha$ stimulation $(10 \mathrm{ng} / \mathrm{ml})$. TNF- $\alpha$ was identified to significantly increase adhesion of THP-1 monocytic cells to HASMCs $(\mathrm{P}<0.05)$. AQEE suppressed monocyte adhesion in a dose-dependent manner (Fig. 2).

Effect of AQEE on TNF- $\alpha$-induced expression of adhesion molecules. The effect of AQEE on the TNF- $\alpha$-induced expression of adhesion molecules in HASMCs was assessed by western blot analysis and cell surface ELISA. Results of the western blot analysis revealed that TNF- $\alpha$ induced ICAM-1 and E-selectin (Fig. 3A and B). AQEE pretreatment inhibited the TNF- $\alpha$-induced upregulation of the adhesion molecules in a dose-dependent manner. Consistent with these observations, ELISA results demonstrated that AQEE reduced adhesion molecule expression on the cell surface of TNF- $\alpha$-stimulated HASMCs (Fig. 3C).

Effect of AQEE on TNF- $\alpha$-induced $N F-\kappa B$ translocation. $\mathrm{NF}-\kappa \mathrm{B}$ activation is crucial for the induction of adhesion molecules by TNF- $\alpha(19,20)$. Therefore, the effect of AQEE on TNF- $\alpha$-induced nuclear translocation of the activated NF- $\kappa \mathrm{B}$ 

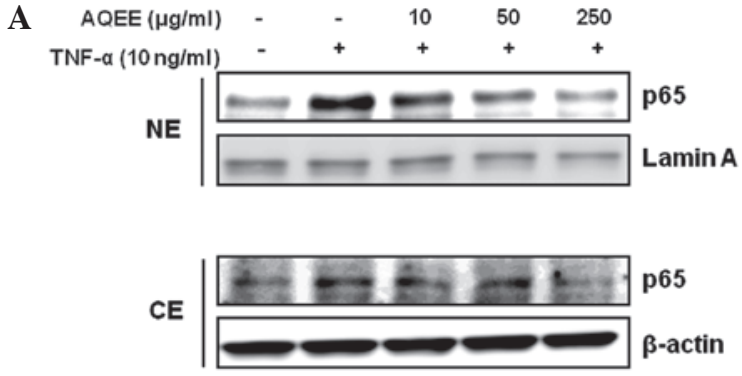

B
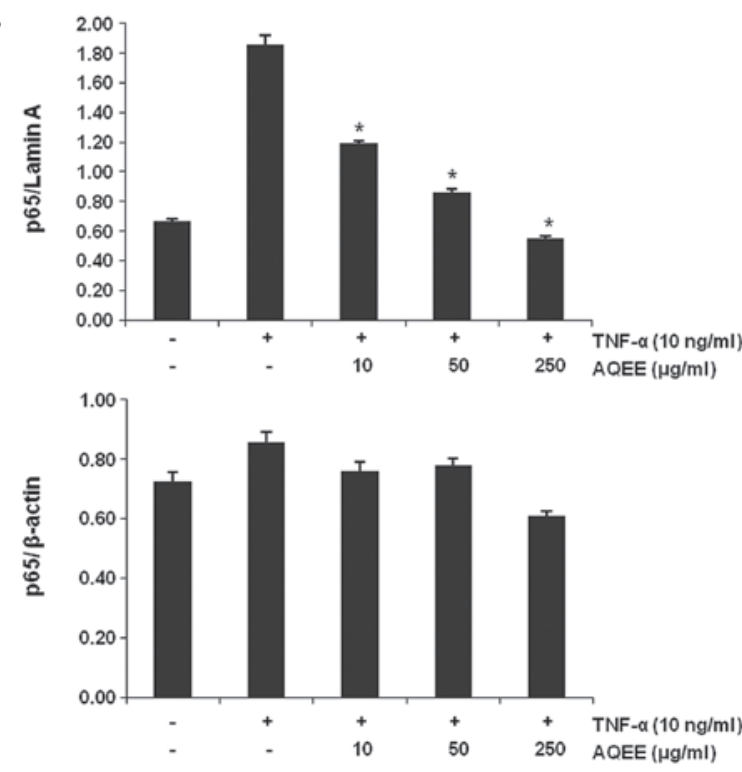

Figure 4. Effects of AQEE on nuclear translocation of NF-kB p65 subunit in TNF- $\alpha$-stimulated HASMCs. (A) Western blot analysis of cytoplasmic and nuclear levels of NF-kB p65 in HASMCs preincubated with AQEE for $2 \mathrm{~h}$ and then treated with TNF- $\alpha(10 \mathrm{ng} / \mathrm{ml})$ for $4 \mathrm{~h}$. Lamin A and $\beta$-actin were used as loading controls for nuclear and cytosolic protein fractions, respectively. (B) Densitometry analysis of western blots demonstrating relative density of $\mathrm{p} 65 / \mathrm{lamin} \mathrm{A}$ or $\mathrm{p} 65 / \beta$-actin. Results are expressed as the mean \pm SEM $(n=3) .{ }^{*} \mathrm{P}<0.05$ compared with untreated TNF- $\alpha$-stimulated cells. NE, nuclear extracts; CE, cytoplasmic extracts; AQEE, Akebia quinato ethanol extract; HASMCs, human aortic smooth muscle cells; TNF- $\alpha$, tumor necrosis factor $\alpha$; NF- $\mathrm{\kappa B}$, nuclear factor $\mathrm{\kappa B}$.

p65 subunit was investigated. Cells were pretreated with various concentrations of AQEE for $2 \mathrm{~h}$ and then stimulated with TNF- $\alpha$ for $4 \mathrm{~h}$. Nuclear and cytoplasmic extracts were then analyzed by western blot analysis. Fig. 4 demonstrates that AQEE decreased p65 NF- $\kappa \mathrm{B}$ nuclear translocation in a dose-dependent manner, indicating that AQEE inhibits TNF- $\alpha$-induced NF- $\kappa \mathrm{B}$ activation.

Effect of AQEE on p38 mitogen-activated protein kinases (MAPKs) in TNF- $\alpha$-stimulated HASMCs. MAPK signaling pathways are also involved in the regulation of adhesion molecule expression $(21,22)$. We identified that 30-min treatment with TNF- $\alpha$ increased phosphorylation (activation) of p38 MAPK. However, pretreatment with AQEE for $2 \mathrm{~h}$ inhibited TNF- $\alpha$-induced p38 MAPK phosphorylation (Fig. 5).

\section{Discussion}

Interactions between aortic smooth muscle cells and monocytes through proinflammatory mediators contribute to
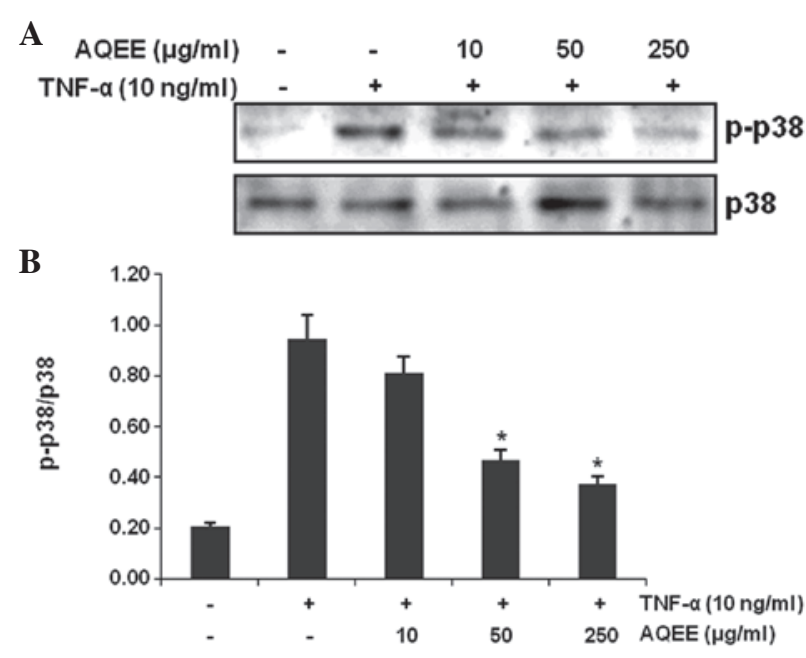

Figure 5. Effect of AQEE on TNF- $\alpha$-induced p38 activation (A). Western blot analysis of the expression and phosphorylation of p38 MAPK in HASMCs pretreated with AQEE for $2 \mathrm{~h}$ and then stimulated with TNF- $\alpha$ (10 ng/ $\mathrm{ml}$ ) for $30 \mathrm{~min}$. (B) Densitometry analysis of western blots demonstrating relative amounts of phospho-p38 and total p38. Results are expressed as the mean \pm SEM $(n=3)$. $\mathrm{P}<0.05$, compared with untreated TNF- $\alpha$-stimulated cells. AQEE, Akebia quinata ethanol extract; HASMCs, human aortic smooth muscle cells; TNF- $\alpha$, tumor necrosis factor $\alpha$; MAPK, mitogenactivated protein kinase.

inflammation in the vascular wall and the progression of atherosclerosis (10). For example, inflammatory cells secrete TNF- $\alpha$, which upregulates the adhesion molecule expression and promotes the formation of atherosclerotic lesions (2).

In the present study, AQEE suppressed the TNF- $\alpha$-induced expression of adhesion molecules (ICAM-1 and E-selectin) and COX-2 and inhibited monocyte adhesion to HASMCs. These results indicate that $\mathrm{AQEE}$ is able to reduce TNF- $\alpha$-induced inflammatory response in aortic smooth muscle cells.

In the majority of unstimulated cells, $N F-\kappa B$ is present as an inactive, IкB-bound complex in the cytoplasm. Following cytokine stimulation, activated $N F-\kappa B$ translocates into the nucleus and initiates transcription of genes involved in inflammation, including COX-2 (23-25). In addition, TNF- $\alpha$ activation of the transcription factor $\mathrm{NF}-\kappa \mathrm{B}$ is required for the upregulation of muscle cell adhesion molecules (20). In the present study, AQEE was identified to attenuate TNF- $\alpha$-induced NF- $\kappa$ B activation. Previous studies (19) have shown that MAPK signaling pathways are also involved in the regulation of $N F-\kappa B$ activation in response to TNF- $\alpha$. This study has demonstrated that AQEE suppressed TNF- $\alpha$-stimulated p38 phosphorylation, however, the extract had little effect on extracellular signal-regulated kinases (ERK)1/2 or c-Jun $\mathrm{N}$-terminal kinase phosphorylation (data not shown). These observations indicate that AQEE prevents the upregulation of cell adhesion molecules by interfering with gene transcription.

In summary, the present study has demonstrated that AQEE inhibits vascular inflammation in TNF- $\alpha$-stimulated HASMCs, preventing the upregulation of adhesion molecules and COX-2 by blocking NF- $\mathrm{NB}$ and p38 MAPK signaling pathways. These observations may provide a foundation for the development of AQEE as an anti-inflammatory agent to prevent vascular inflammatory disorders. 


\section{Acknowledgements}

The present study was supported by the Discovery of Herbal Medicine for the Prevention of Prehypertension Project (K12202) and the Construction of the Basis for Practical Application of Herbal Resources (K11020) funded by the Ministry of Education, Science and Technology of Korea to the Korea Institute of Oriental Medicine.

\section{References}

1. Lusis AJ: Atherosclerosis. Nature 407: 233-241, 2000

2. Ross R: Atherosclerosis - an inflammatory disease. N Engl J Med 340: 115-126, 1999.

3. Bevilacqua MP, Nelson RM, Mannori G and Cecconi O: Endothelial-leukocyte adhesion molecules in human disease. Annu Rev Med 45: 361-378, 1994.

4. Bobryshev YV, Lord RS, Rainer SP and Munro VF: VCAM-1 expression and network of VCAM-1 positive vascular dendritic cells in advanced atherosclerotic lesions of carotid arteries and aortas. Acta Histochem 98: 185-194, 1996.

5. O'Brien KD, McDonald TO, Chait A, Allen MD and Alpers CE: Neovascular expression of E-selectin, intercellular adhesion molecule-1 and vascular cell adhesion molecule-1 in human atherosclerosis and their relation to intimal leukocyte content. Circulation 93: 672-682, 1996.

6. O'Brien KD, Allen MD, McDonald TO, Chait A, Harlan JM, Fishbein D, McCarty J, Ferguson M, Hudkins K and Benjamin CD: Vascular cell adhesion molecule-1 is expressed in human coronary atherosclerotic plaques. Implications for the mode of progression of advanced coronary atherosclerosis. J Clin Invest 92: 945-951, 1993.

7. Owens GK, Kumar MS and Wamhoff BR: Molecular regulation of vascular smooth muscle cell differentiation in development and disease. Physiol Rev 84: 767-801, 2004.

8. Falk E: Pathogenesis of atherosclerosis. J Am Coll Cardiol 47 (Suppl 8): C7-C12, 2006.

9. Braun M, Pietsch P, Schrör K, Baumann G and Felix SB: Cellular adhesion molecules on vascular smooth muscle cells. Cardiovasc Res 41: 395-401, 1999.

10. Jang Y, Lincoff AM, Plow EF and Topol EJ: Cell adhesion molecules in coronary artery disease. J Am Coll Cardiol 24: 1591-1601, 1994.

11. Davies MJ, Gordon JL, Gearing AJ, Pigott R, Woolf N, Katz D and Kyriakopoulos A: The expression of the adhesion molecules ICAM-1, VCAM-1, PECAM and E-selectin in human atherosclerosis. J Pathol 171: 223-229, 1993.
12. Libby P and Li H: Vascular cell adhesion molecule-1 and smooth muscle cell activation during atherogenesis. J Clin Invest 92: 538-539, 1993.

13. Printseva OYu, Peclo MM and Gown AM: Various cell types in human atherosclerotic lesions express ICAM-1. Further immunocytochemical and immunochemical studies employing monoclonal antibody 10F3. Am J Pathol 140: 889-896, 1992.

14. Huo Y and Ley K: Adhesion molecules and atherogenesis. Acta Physiol Scand 173: 35-43, 2001.

15. Kitaoka F, Kakiuchi N, Long C, Itoga M, Mitsue A, Mouri C and Mikage M: Molecular characterization of akebia plants and the derived traditional herbal medicine. Biol Pharm Bull 32: 665-670, 2009.

16. Mimaki Y, Doi S, Kuroda M and Yokosuka A: Triterpene glycosides from the stems of Akebia quinata. Chem Pharm Bull 55: 1319-1324, 2007

17. Choi J, Jung HJ, Lee KT and Park HJ: Antinociceptive and anti-inflammatory effects of the saponin and sapogenins obtained from the stem of Akebia quinata. J Med Food 8: 78-85, 2005.

18. Tsuchiya S, Yamabe M, Yamaguchi Y, Kobayashi Y, Konno T and Tada K: Establishment and characterization of a human acute monocytic leukemia cell line (THP-1). Int J Cancer 26: 171-176, 1980.

19. Chen C, Chou C, Sun Y and Huang W: Tumor necrosis factor alpha-induced activation of downstream NF-kappaB site of the promoter mediates epithelial ICAM-1 expression and monocyte adhesion. Involvement of PKCalpha, tyrosine kinase and IKK2, but not MAPKs, pathway. Cell Signal 13: 543-553, 2001.

20. Collins T, Read MA, Neish AS, Whitley MZ, Thanos D and Maniatis T: Transcriptional regulation of endothelial cell adhesion molecules: NF-kappa B and cytokine-inducible enhancers. FASEB J 9: 899-909, 1995.

21. Ju JW, Kim SJ, Jun CD and Chun JS: p38 kinase and c-Jun $\mathrm{N}$-terminal kinase oppositely regulates tumor necrosis factor alpha-induced vascular cell adhesion molecule-1 expression and cell adhesion in chondrosarcoma cells. IUBMB Life 54: 293-299, 2002.

22. Ho AW, Wong CK and Lam CW: Tumor necrosis factor-alpha up-regulates the expression of CCL2 and adhesion molecules of human proximal tubular epithelial cells through MAPK signaling pathways. Immunobiology 213: 533-544, 2008.

23. Brasier AR: The nuclear factor-kappaB-interleukin-6 signalling pathway mediating vascular inflammation. Cardiovasc Res 86: 211-218, 2010.

24. Pahl HL: Activators and target genes of Rel/NF-kappaB transcription factors. Oncogene 18: 6853-6866, 1999.

25. Waddick KG and Uckun FM: Innovative treatment programs against cancer: II. Nuclear factor-kappaB (NF-kappaB) as a molecular target. Biochem Pharmacol 57: 9-17, 1999. 